\title{
О ПРОБЛЕМАХ ЛЕЧЕНИЯ РАСПРОСТРАНЕННОГО ГНОЙНОГО ПЕРИТОНИТА
}

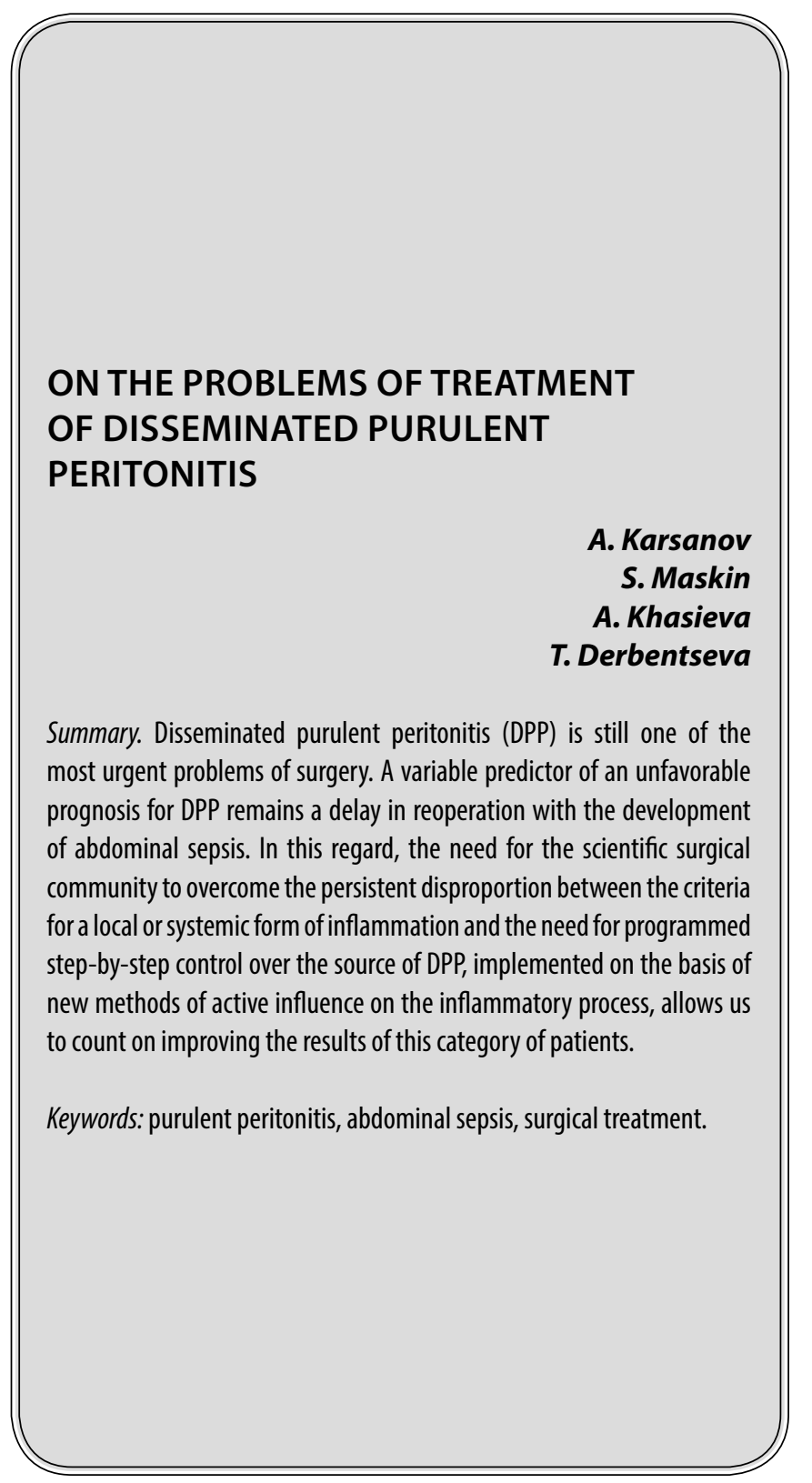

Л ечение пациентов с распространенным гнойным перитонитом (РГП) было и остается одной из наиболее сложных по исходам и дискутабельных по выбору приоритетной лечебной концепции областей современной хирургии $[1,2,3,4]$. На современном этапе стратегический подход к лечению пациентов с РГП определяется в рамках понятия "осложненная внутрибрюшная хирургическая инфекция" (ОВБИ) [1, 3]. Осложненные ВБИ чаще возникают вторично, а наиболее тяжелые их
Карсанов Алан Мухарбекович К.м.н., дочент, ФГБОУ ВО «Северо-Осетинская государственная медицинская академия»

(2. Владикавказ)

karsan@inbox.ru

Маскин Сергей Сергеевич

Д.м.н., професссор, ФГБОУВО «Волгоградский государственный медицинский университет»

(2. Волгоград)

maskins@bk.ru

Хасиева Алана Анатольевна

Врач-хирург, ГБУз «Республиканская клиническая больнича скорой медичинской помощи» (2. Владикавказ) a.khasiyeva@list.ru

Дербенцева Татьяна Викторовна

К.м.н., ассистент, ФГБОУВО «Волгоградский государственный медицинский университет»

(2. Волгоград)

TVDerbentseva@volgmed.ru

Аннотация. Распространенный гнойный перитонит (РГП) по-прежнему остается одной из наиболее актуальных проблем хирургии. Переменным предиктором неблагоприятного прогноза при РГП остается задержка с повторной операцией при развитии абдоминального сепсиса. В этой связи, важнейшее значение имеет необходимость преодоления научным хирургическим сообществом сохраняющейся дискорреляции между критериями локальной или системной формы воспаления и потребностью в программированном этапном контроле над источником РГП, реализованные на основе новых методов активного воздействия на воспалительный процесс позволяют рассчитывать на улучшение результатов этой категории пациентов.

Ключевые слова: гнойный перитонит, абдоминальный сепсис, хирургическое лечение.

формы составляют понятие "абдоминальный сепсис" (AC) $[1,5]$. Доля РГП в общей структуре вторичного перитонита достигает $21 \%$, с общей частотой разнообразных осложнений до $68 \%[3,4,6]$.

Результаты крупномасштабного общемирового исследования CIAOW study показали, что распространенный характер перитонита имел место в 43,6\%, остальные случаи $(56,4 \%)$ были классифицированы, как локальные 
инфекции [7]. Полиорганная недостаточность и септический шок были констатированы у 14,2\% пациентов, а всего интенсивный этап лечение потребовался 29,8\% больных. Повторные хирургические мероприятия по контролю над источником ОВБИ потребовались в 11,7\% случаев, а релапаротомии были выполнены $11,3 \%$ пациентов. Общая госпитальная летальность составила 10,5\%. Независимыми предикторами прогноза летального исхода при многофакторном анализе были: пожилой возраст (относительный риск (ОР) смерти составил 1,1), наличие перфорации кишечника $(\mathrm{OP}=2,8)$, задержка с первичной либо повторной операцией более чем на 24 часа $(\mathrm{OP}=1,8)$, потребность нахождения В отделении интенсивной терапии $(\mathrm{OP}=5,9)$ и выявленная у пациента иммуносупрессивность $(\mathrm{OP}=3,8)$ [7].

При РГП по-прежнему сохраняется неоднозначность в определении дифференциальных критериев локальной инфекции и АС, поскольку отсутствует у представителей различных хирургических школ единое понимание патогенетических механизмов формирования системной альтерации при ОВБИ $[2,4,5,8]$. На наш взгляд именно поэтому пока не решена задача по своевременной диагностике и созданию оптимальной лечебной концепции при РГП, учитывающая зависимость клинической ситуации от различных первичных заболеваний и травм органов брюшной полости, а также от условий (внебольничных и нозокомиальных) ее возникновения $[4,6,9]$.

К сожалению, хирургическая тактика при РГП не достаточно четко дифференцирована в зависимости от характера локального либо системного пути развития воспаления $[1,3,6]$, а, как показывает практика, на современном этапе выбор эффективной лечебной программы при абдоминальной катастрофе уже невозможен без учета этих факторов $[2,4,5,10]$.

Бесспорно, что успешное лечение больных с ОВБИ базируется на своевременной верификации и точной топической локализации гнойно-деструктивного процесса в брюшной полости [11]. Несмотря на современный уровень развития систем медицинской визуализации приходится констатировать, что в ряде клинических ситуаций выявление ОВБИ - это в первую очередь задача клинической диагностики [10].

Однако в целом ряде случаев, в первую очередь у пациентов, находящихся в критических состояниях, клиническая диагностика ненадежна и затруднена из-за сочетанной травмы, шока, дыхательной недостаточности, бессознательного состояния или других сопутствующих заболеваний [1]. Именно в таких ситуациях остается высокой частота диагностических ошибок, приводящих к выполнению напрасных или неоправданно запозда- лых оперативных вмешательств, с соответствующим увеличением числа осложнений $[3,7]$.

В мире отмечен безусловный прогресс в развитии систем медицинской визуализации при ОВБИ, в том числе и с лечебно-навигационными целями. С позиций доказательной медицины есть уже все основания постулировать, что визуализационные технологии и базирующееся на их использовании малоинвазивное лечение являются методами выбора при целом ряде ОВБИ [10]. Расширяется и становится доминирующей практика использования видеолапароскопических технологий [11]. Достигнуты определенные успехи в оптимизации стратегии и совершенствовании тактики использования антимикробной химиотерапии и интенсивной терапии критических септических больных с ОВБИ $[1,3,5]$.

Отдельную, чрезвычайно интересную, сложную и комплексную проблему представляет вторичный распространенный гнойный и каловый перитонит, возникший вследствие заболеваний и травм толстой кишки [8, $11,83,86,113]$. Несмотря на все достижения современной хирургии, интенсивной терапии и клинической фармакологии, именно толстокишечный генез ОВБИ является одним из основных факторов неудовлетворительного прогноза. В подобных ситуациях летальность при АС редко удается снизить ниже $30 \%$ [4, 52, 86, 113$]$.

К основным факторам неблагоприятного прогноза лечения пациентов с ОВБИ относятся:

- исходный проблемный соматический статус пациентов, которые в своем большинстве относятся к пожилому и старческому возрасту;

- нутриционный дефицит и саркопения;

иммуносупрессия,

- органно-системная дисфункция и возникновение септического шока;

- высокая степенью ранней контаминации ассоциациями высокопатогенной микрофлоры;

- неадекватный хирургический контроль источника РГП (Sourse control);

- развитие синдрома интраабдоминальной гипертензии;

- высокий риск инфицирования внутрибольничными патогенами, особенно при необходимости в релапаротомии либо - лапаростомии;

- затяжное течение перитонита, необходимость коррекции синдрома кишечной недостаточности и сложности стандартизации при обеспечении целостности дигестивного тракта в различных клинических ситуациях [12].

Значение последнего обстоятельства трудно переоценить, поскольку при длительном, затяжном течении ОВБИ характерным является формирование третичного 
перитонита, что само по себе повышает риск летальности до $50-64 \%[1,2,7,9]$.

AC, являясь второй причиной госпитальной летальности в ряду других источников сепсиса, предъявляет особые требования к местно-направленным способами хирургического контроля источника ОВБИ и синдрома интраабдоминальной гипертензии $[1,5,12,13]$. Топография зон бактериальной альтерации при РГП чрезвычайно сложна для выполнения "идеального" хирургического вмешательства, ввиду чего источник инфекции не всегда может быть радикально ликвидирован в один этап [4, 14, 15].

Особенно сложным остается выбор объема оперативного лечения ОВБИ при осложнениях колоректального рака (КРР) как наиболее частой клинической формой реализации этого типа воспалительных процессов в брюшной полости [16, 17]. Неудовлетворенность хирургов результатами лечения пациентов с РГП именно бластоматозной толстокишечной этиологии является постоянным стимулом к пересмотру некоторых аспектов хирургической тактики, основанному на новых методах активного воздействия на воспалительный процесс в брюшной полости и профилактике системных осложнений.

По данным бразильских хирургов, среди неотложных показаний к оперативному лечению КРР 23\% составляли перфорации опухоли толстой кишки, а в остальных случаях это была опухолевая непроходимость [18]. Частота летальности при этих двух вариантах осложнений рака составила 33,6\% и 20\% соответственно. Аналогичная частота перфораций (23,6\%) толстой кишки выявлена в Австралийском исследовании [17], а 47\% из них были ассоциированы с КРP.

При различных осложнениях, а особенно при их сочетании, перитонит при неопластическом процессе толстой кишки встречается в 8,8-34,9\% случаев [4, 7, 16, 18]. Потребность в релапаротомии после неотложных операций по поводу КРР достигает 7,7-45\%, причем только половина из них бывает обусловлена несостоятельностью анастомозов, в то время как остальные $50 \%$ - прогрессированием исходного перитонита $[4,7$, $15,17]$. При отсутствии исходного толстокишечного перитонита потребность в релапаротомии значительно ниже (2,4-4,5\%), в основном - за счет несостоятельности анастомозов, частота которой при неотложной резекции толстой кишки широко варьирует (2,5-18,7\%) и внутрибрюшных абсцессов (7,3-11,6\%) $[2,4,7,15,16]$.

По результатам исследования С.А. Алиева и соавт. [19], в общей структуре послеоперационных внутрибрюшных осложнений, гнойно-септические осложнения (абсцессы и распространенный перитонит) занимают лидирующее место (88\%), достигая 6,8\% от общего числа в группе неотложно оперированных по поводу КРР пациентов. В структуре внутрибрюшных осложнений доля перитонита составила 78,6\%, а частота несостоятельности ургентно наложенных анастомозов - 9,3\% от всех первично-восстановительных операций.

Согласно данным L.H. Iversen и соавт. [20] у 24,4\% всех пациентов, перенесших неотложное оперативное вмешательство по поводу осложнений КРР, развиваются различные, в том числе - инфекционно-воспалительные осложнения. Летальность в осложненной группе достигала невиданных цифр в 57,8\% и в основном была обусловлена прогрессированием полиорганной недостаточности, а независимыми факторами риска смерти были: возраст старше 71 года, мужской пол, оценка по ASA $\geq$ III баллов, перфорация опухоли, паллиативный характер операции, вынужденная спленэктомия.

По результатам исследования E. J. Morris и соавт. [21], основанного на анализе исходов хирургического лечения более 160 тыс. пациентов КРР в Великобритании, летальность при ургентных операциях составила 14,9\%, по сравнению с 5,8\% - при плановом лечении. Даже в случае успешного лечения гнойно-воспалительных осложнений КРР, сам факт неотложного лечения рака и системный воспалительный синдром являются независимыми факторами сокращения, как общей выживаемости (с 57,5\% - после плановой, до 39,1\% - после экстренной операции) [22], так и канцер-специфичной выживаемости пациентов $[17,23]$. При анализе годичной летальности у оперированных по поводу КРР пожилых пациентов, J.W. Dekker и соавт. [24] констатировали этот показатель на уровне 13,2\% - после плановых и 43\%после экстренных операций.

По данным P.E. Teloken и соавт. [17], относительный риск смерти после срочной операции составил 2,65. Наиболее значимыми предикторами госпитальной летальности среди оперированных по поводу КРР являются: экстренная операция, стадия опухоли, возраст, лёгочная и сердечная недостаточность $[25,26]$.

Таким образом, на современном этапе лечение пациентов с распространенным гнойным перитонитом, осложненным абдоминальным сепсисом, по-прежнему представляет актуальную проблему в силу целого ряда разнообразных клинических и патогенетических факторов. Именно учет наиболее значимых ресурсов для выбора оптимальной тактики лечения этой категории пациентов в реальной клинике не налажен и, соответственно, не используется в качестве стандартного принципа лечения. 
Хирурги всего мира пока не могут похвастаться, что имеют в своем арсенале безоговорочно эффективный маркер локального и генерализованного пути развития распространенного гнойного перитонита и именно вследствие этого не могут прогнозировать риск раннего развития синдрома полиорганной дисфункции.

Для повышения эффективности лечения этой категории пациентов необходимы многоцентровые, комплексные исследования по прецизионной детализации патогенеза наиболее тяжелых форм распространенной внутрибрюшной инфекции. И лишь на этой базе оправдан поиск и совершенствование оптимальных тактических подходов, разработка новых методов активного воздействия на воспалительный процесс в брюшной полости, направленных на профилактику системных осложнений распространенного гнойного перитонита.

\section{ЛИТЕРАТУРА}

1. Абдоминальная хирургическая инфекция. Российские национальные рекомендации / Под ред. Б. Р. Гельфанда, А. И. Кириенко, Н. Н. Хачатрян.- М.: МИА, 2018. - 164 c.

2. Власов А.П., Трофимов В. А., Григорьева Т. И., Шибитов В. А., Власов П. А. Энтеральный дистресс-синдром в хирургии: понятие, патогенез, диагностика // Хирургия.—2016. - № 11.—C. 48-53.

3. Sartelli M., Chichom-Mefire A., Labricciosa F.M. et. al. The management of intra-abdominal infections from a global perspective: 2017 WSES guidelines for management of intra-abdominal infections // World J. Emerg. Surg. — 2017. — Vol.12. — P. 29.— Режим доступа: https://doi.org/10.1186/s13017-0170141-6.

4. Маскин С.С., Гольбрайх В. А., Дербенцева Т. В. и др. Программные и экстренные релапаротомии в лечении распространенного перитонита // Вестник Волгоградского государственного медицинского университета. - 2012. — № 4. - С. 105-107.

5. Сепсис: классификация, клинико-диагностическая концепция и лечение. Практическое руководство / Под ред. Б. Р. Гельфанда // М.: МИА, $2017 ; 406$ с.

6. Карсанов А.М., Маскин С. С., Климович И. Н. и др. Варианты тактических решений при осложненной интраабдоминальной инфекции // Московский хирургический журнал.—2014.—№ 2.- С. 67-72.

7. Sartelli M., Catena F., Ansaloni L. et. al. Complicated intra-abdominal infections worldwide: the definitive data of the CIAOW Study // World J. Emerg. Surg.2014.—Vol.9.—P. 37.— Режим доступа: https://www.ncbi.nlm.nih.gov/pmc/articles/PMC4039043/.

8. Güsgen C., Schwab R., Willms A. Therapy concepts for diffuse peritonitis: When laparoscopic lavage and when open abdomen? // Chirurg. — 2016.— № 1.— P.34-39.

9. Гольбрайх В.А., Маскин С. С., Бобырин А. В., Карсанов А. М., Дербенцева Т. В., Лопастейский Д. С., Таджиева А. Р. Острые перфоративные язвы у больных с распространенным перитонитом // Вестник экспериментальной и клинической хирургии.— 2012.— № 1.—C. 51-53.

10. Маскин С.С., Шамаев 3. М., Шварцман И. М., Дубровин А. В., Карсанов А. М. Ультразвуковая диагностика в выборе тактики лечения толстокишечной непроходимости // Скорая медицинская помощь. — 2004. — № 3.— С. 106-107.

11. Климович И.Н., Маскин С. С., Дубровин И. А., Карсанов А. М., Дербенцева Т. В. Эндовидеохирургия в диагностике и лечении послеоперационного перитонита // Вестник хирургии им. И. И. Грекова. — 2015.— № 4.—C. 113-116.

12. Абдоминальная хирургическая инфекция (классификация, диагностика, антимикробная терапия): Российские национальные рекомендации / Под ред. Савельева В.С., Гельфанда Б. Р.- М.: Боргес, 2011.— 98 с.

13. Ларичев А. Б. Снова о сепсисе: философия диалектического единства дефиниции и клинической практики // Хирургия.— 2015.— № 10.—C. 84-87.

14. Карсанов А.М., Маскин С. С., Слепушкин В. Д., Карсанова Ф. Д., Дербенцева Т. В., Худиев Э. М. Возможности повышения периоперационной безопасности пациентов при раке толстой кишки // Вест. нац. мед.-хирург. центра им. Н. И. Пирогова. — 2015.— № 3.— С. 43-47.

15. Маскин С.С., Дербенцева Т. В., Карсанов А. М., Иголкина Л. А., Ермолаева Н. К., Лопастейский Д. С. Плановые и срочные релапаротомии при послеоперационных внутрибрюшных осложнениях // Кубанский научный медицинский вестник. - 2013.— № 7.— С. 101-106.

16. Mik M., Magdzinska J., Dziki L. et al. Relaparotomy in colorectal cancer surgery — do any factors influence the risk of mortality? A case controlled study // Int. J. Surg. - 2014. - Vol. 12. № 11.—P. 1192-1197.

17. Teloken P.E., Spilsbury K., Levitt M. et al. Outcomes in patients undergoing urgent colorectal surgery // ANZ J. Surg. — 2014.— Vol. 84. № 12.— P. $960-964$.

18. Teixeira F., Akaishi E. H., Ushinohama A.Z. et. al. Can we respect the principles of oncologic resection in an emergency surgery to treat colon cancer? // World J. Emerg. Surg. — 2015.—Vol. 10.— P. 5.— Режим доступа: https://www.ncbi.nlm.nih.gov/pubmed/26191078.

19. Алиев С.А., Алиев Э.С., Зейналов Б. М. Послеоперационные внутрибрюшные осложнения в хирургии рака ободочной кишки, осложненного кишечной непроходимостью и перфорацией опухоли // Вестник хирургии.— 2015.— № 5.—C. 98-104.

20. Iversen L.H., Bülow S., Christensen I. J. et. al. Danish colorectal cancer group: Postoperative medical complications are the main cause of early death after emergency surgery for colonic cancer // Br. J. Surg. — 2008. - Vol. 95. № 8. - P. 1012-1019.

21. Morris E.J., Taylor E. F., Thomas J. D. et al. Thirty-day postoperative mortality after colorectal cancer surgery in England // Gut. — 2011.— Vol. 60. № 6. — P. 806813.

22. Sucullu I., Ozdemir Y., Cuhadar V. et al. Comparison of emergency surgeries for obstructed colonic cancer with elective surgeries: A retrospective study // Pak. J. Med. Sci.— 2015.—Vol.31. № 6.—P. 1322-1327. 
23. van Eeghen E. E., den Boer F. C., Loffeld R. J. Thirty days post-operative mortality after surgery for colorectal cancer: a descriptive study // J. Gastrointest. Oncol.2015.—Vol.6. № 6. - P. 613-617.

24. Dekker J.W., Gooiker G. A., Bastiaannet E. et al. Steering committee of the 'quality information system colorectal cancer' project. Cause of death the first year after curative colorectal cancer surgery; a prolonged impact of the surgery in elderly colorectal cancer patients // Eur. J. Surg. Oncol.— 2014.—Vol.40. № 11.—P. 14811487.

25. van der Sluis F. J., Espin E., Vallribera F. et al. Predicting postoperative mortality after colorectal surgery: a novel clinical model // Colorectal Dis. — 2014.—Vol.16. № 8. - P. 631-639.

26. Маскин С. С., Карсанов А. М., Надельнюк Я. В., Шамаев 3. М. Тактические принципы хирургии непроходимости толстой кишки // Вестник хирургической гастроэнтерологии.—2008.— № 4.—C. 115-116.

( Карсанов Алан Мухарбекович ( karsan@inbox.ru ), Маскин Сергей Сергеевич ( maskins@bk.ru),

Хасиева Алана Анатольевна ( a.khasiyeva@list.ru ), Дербенцева Татьяна Викторовна (TVDerbentseva@volgmed.ru ).

Журнал «Современная наука: актуальные проблемы теории и практики»

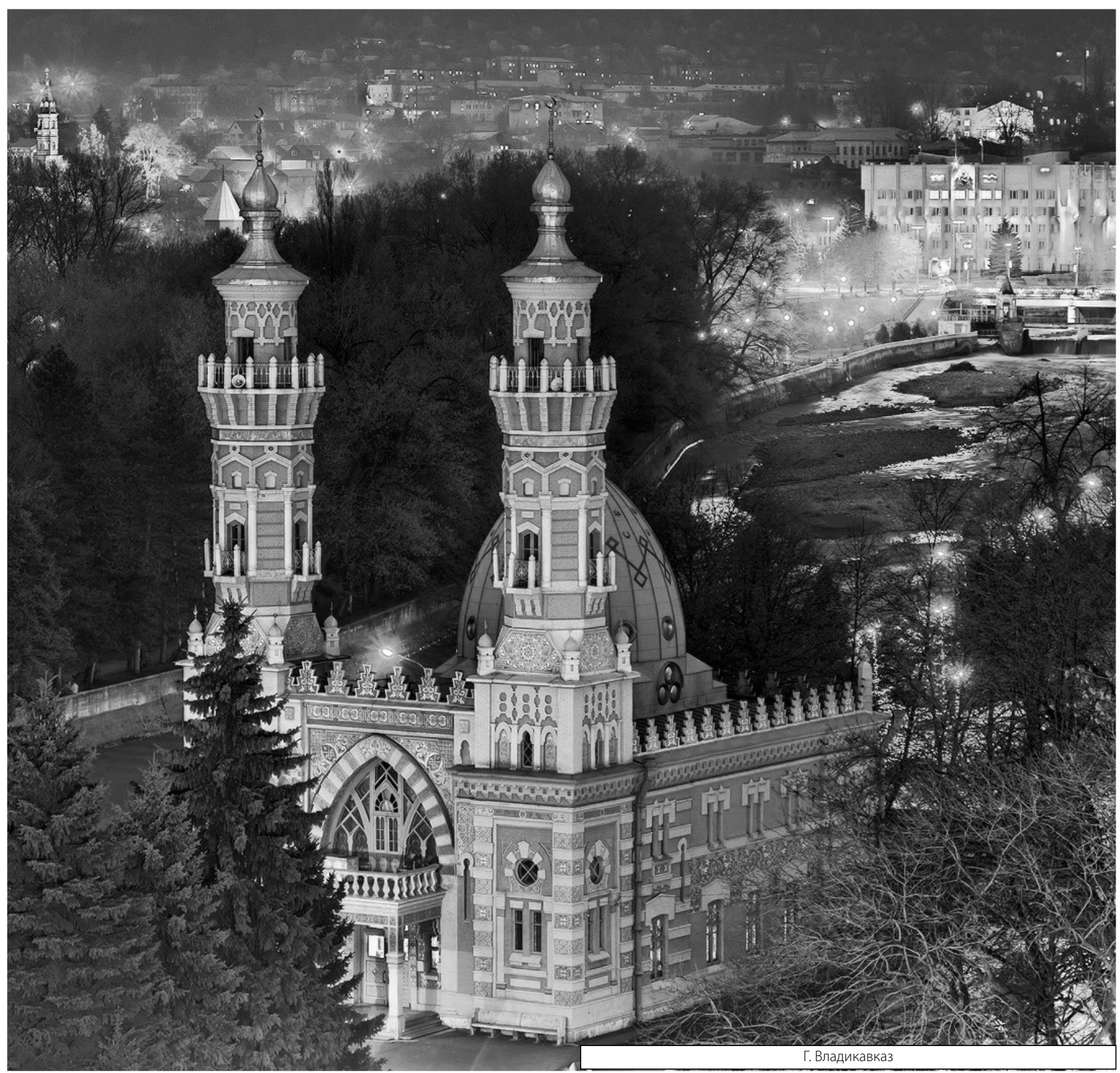

